\title{
The associated regulators and signal pathway in rIL-16/CD4 medi- ated growth regulation in Jurkat cells
}

\author{
Xiao Ming ZHANG, Yong Hua XU* \\ Lab of Molecular and Cellular Oncology, Institute of Biochemistry and Cell Biology, Shanghai Institutes for \\ Biological Sciences, Chinese Academy of Sciences, 320 Yueyang Road, Shanghai 200031, China
}

\begin{abstract}
IL-16 is a ligand and chemotactic factor for CD4 ${ }^{+} \mathrm{T}$ cells. IL-16 inhibits the CD3 mediated lymphocyte activation and proliferation. The effects of IL-16 on the target cells are dependent on the cell type, the presence of co-activators etc. To understand the regulation function and mechanism of IL-16 on target cells, we used a 130 a.a. recombinant IL-16 to study its effects on the growth of Jurkat T leukemia cells in vitro. We found that the rIL-16 stimulated the proliferation of Jurkat cells at low dose $\left(10^{-9} M\right)$, but inhibited the growth of the cells at higher concentration $\left(10^{-5} \mathrm{M}\right)$. Results showed that $10^{-5} \mathrm{M}$ of rIL-16 treatment induced an enhanced apoptosis in Jurkat cells. The treatment blocked the expression of FasL, but upregulated the c-myc and Bid expression in the cells. Pre-treatment of PKC inhibitor or MEK1 inhibitor markedly increased or decreased the rIL-16 induced growth-inhibiting effects on Jurkat cells, respectively. The results suggested that the rIL-16 might be a regulator for the growth or apoptosis of Jurkat cells at a dose-dependent manner. The growth-inhibiting effects of rIL-16 might be Fas/FasL independent, but, associated with the activation of PKC, up-regulated expression of c-Myc and Bid, and the participation of the ERK signal pathway in Jurkat cells.
\end{abstract}

Key words: IL-16, Jurkat cells, growth regulation.

\section{INTRODUCTION}

Pro-IL-16 is a 631 amino acid precursor molecule [1],[2], which can be cleaved by caspase into two parts. The $\mathrm{N}$-terminal part is kept in the cytoplasm [3], and the C-terminal is a secreted peptide containing 121 amino acids. Researches have shown that the recombinant IL-16 C-terminal 130 a.a. has same bioactivity as the natural secreted human IL-16[1], [4],[5].

The human secreting IL-16 is the natural soluble ligand of CD4 molecule[4], [6], [7]. It stimulates a series of signals mediated by $\mathrm{CD} 4$, resulting in the activation of p56lck, increases of intracellular $\mathrm{Ca}^{++}$

* Corresponding author: Prof. Yong Hua XU

Tel/Fax: 0086-21-64711349, E-mail: yhxu@sunm.shcnc.ac.cn Received Jul-5-2002 Revised Oct-25-2002 Accepted Nov-7-2002 and phosphatidylinositol 1, 4, 5-trisphosphate and the increased expression of IL-2 receptor[4],[8-10]. The signals by CD4 can activate the $\mathrm{T}$ cell when there is another co-stimulator. The cross-linking of cell surface CD4 with anti-CD4 mAb or HIV-1 gp120 may mediate apoptosis rather than activation of the $\mathrm{CD}^{+}{ }^{+} \mathrm{T}$ cell[11-15]. Interestingly, another cytokine, IL-2, can also prime $\mathrm{T}$ cells for cell death in addition to its activity in activation and proliferation of $\mathrm{T}$ cells [16]. All those results indicated that the activation and cell death are conditional events, the difference is very much dependent on the amount of stimuli, cell type, and the presence of co-activators etc.

As reported here, we have investigated the possible role of rIL-16 to Jurkat T leukemia cells. We found that the rIL-16 showed the growth-stimulating activity at $10^{-9} \mathrm{M} / \mathrm{L}$ to Jurkat cells, but a growthinhibiting activity was detected at higher concentra- 
tion $\left(10^{-5} \mathrm{M} / \mathrm{L}\right)$ of IL-16 caused by an enhanced apoptosis in the cells. The IL-16 induced growth inhibition in jurkat cells was Fas/FasL independent and may related with the activation of c-Myc, Bid and PKC. The inhibitor of MEK1 blocked the effect of rIL-16 on Jurkat cells. The results indicated that the rIL-16 might regulate the growth and apoptosis through the up-regulation of the expression of c-Myc, Bid and the activation of PKC. The ERK pathway was closely associated to the IL-16 regulated proliferation and apoptosis in Jurkat calls.

\section{MATERIALS AND METHODS}

\section{Cells and cultures}

Jurkat T leukemia cells were from Shanghai Cell Bank, Chinese Academy of Sciences. The cells were cultured in RPMI-1640 medium supplemented with $10 \%$ fetal bovine serum, $25 \mathrm{mM}$ HEPES buffer, $100 \mathrm{U} / \mathrm{ml}$ penicillin, and $100 \mu \mathrm{g} / \mathrm{ml}$ streptomycin.

\section{Antibodies}

Anti-IL-16 monoclonal antibody was a product from Yes Biotech Lab, Canada. Rabbit anti human CD4, CD8, FasL antibodies, and FITC-conjugated goat anti-rabbit Ig were purchased from Santa Cruz Biotech. Inc.

\section{Recombinant human IL-16}

Human PBMCs were obtained from the venous blood of healthy normal human volunteers by density centrifugation on Ficoll-Paque (Pharmacia Fine Chemicals).

RNA was isolated from PHA-stimulated PBMC cells using Trizol (Gibco/BRL). Reverse transcription was performed in $30 \mu \mathrm{l}$ final volume containing $0.5 \mu \mathrm{g}$ total RNA which was incubated for $15 \mathrm{~min}$ at $65^{\circ} \mathrm{C}$ before addition of $0.25 \mathrm{~m} \mathrm{M}$ mix dNTPs, $1 \times$ reverse transcriptase (RT) buffer (MBI Fermentas), RNasin (4U), DTT $10 \mathrm{~m} M$, random primer $2 \mu M$ and 10UM-MLVRT(MBI Fermentas). The reaction was allowed $1 \mathrm{~h}$ at $37^{\circ} \mathrm{C}$ and $5 \mathrm{~min}$ at $95{ }^{\circ} \mathrm{C}$. The cDNA product of reverse transcription was amplified in the presence of IL-16-specific primers flanked with a BamH 1 site at 5 ' end of forward and a Cla 1 site at 3 ' end of reverse. The primers were 5'-CGC GGA TCC ATG CCC GAC CTC AAC TCC-3' and 5'-CCA TCG ATC AGC ATG TCC TGC CTA GGA G-3'. Then, the PCR product was digested with BamH 1 and $\mathrm{Cla}$ 1, and cloned into pBluescript (SK) vector. After sequence confirmation, the IL-16 fragment was re-cloned into E.coli expression vector pT7-7His and expressed in BL-21 cells under IPTG induction.

\section{RT-PCR analysis of gene expression}

We adopted semi-quantitative RT-PCR to detect the expression level of the target genes. $\beta$-actin was used as internal control. cDNA $(1 \mu \mathrm{l})$ was added to reaction mixtures (50 $\mu \mathrm{l}$ total volume) containing $1 \times$ PCR buffer, $200 \mu M$ dNTPs (Pharmacia Biotech),
$1 \mu \mathrm{M}$ of forward and reverse primers, $5 \mathrm{U}$ Taq DNA polymerase, and $1.5 \mathrm{mM} \mathrm{MgCl}$. The primers are as follows: $\beta$-actin (360bp): $5^{\prime}$ ACACTGTGCCCATCTACGAGGGG-3, and 5' ATGATGGAG TTGAAGGTAGTTTCGTGGAT-3' ; FasL (450bp): 5' - ATGTTTCAGCTC TTCCAC-3' and 5' AGAGAGAGCTCAGATACG-3' ; $\operatorname{Bid}(600 \mathrm{bp})$ : 5' GCTGCCCAGCATATGGACTGTGAGGTCAAC-3' ; and 5' CTTCTGGAA GGATCCGTTCAGTCCATCCCATTTCTG-3' ; c-Myc (442bp): 5' -GCCCACCACCAGCAGCGACTC-3' , and 5'-CTTGGGGGCCTT TTCATTGTTTTC-3' . PCR reactions were conducted in a Peltier Thermal Cycler PTC-100 (MJ Research company). The PCR involved reactions at $94{ }^{\circ} \mathrm{C}$ for $30 \mathrm{~s}$, annealing at $55{ }^{\circ} \mathrm{C}$ for $30 \mathrm{~s}$ and extension at $72{ }^{\circ} \mathrm{C}$ for $1 \mathrm{~min}$. PCR products were separated by electrophoresis on $1.5 \%$ agarose gel and identified by fragment size.

\section{Western blot analysis}

The protein extractions were analyzed by Western blot. In brief, $10 \mathrm{mg}$ of total protein extract of Jurkat cells was separated by SDS-PAGE, transferred onto nitrocellulose membrane and probed with mouse anti-FasL monoclonal antibody and second antibody. Finally, the band was developed with diaminobenzidine.

\section{PI stain and FACS}

Jurkat cells $\left(5 \times 10^{6} / \mathrm{ml}\right)$ were washed twice with PBS and incubated for $25 \mathrm{~min}$ at $4{ }^{\circ} \mathrm{C}$ with $4 \%$ formaldehyde. After three washes in PBS, cells were incubated with fresh PI stain solution $(5 \mu \mathrm{g} / \mathrm{ml} \mathrm{PI}$ and $50 \mu \mathrm{g} / \mathrm{ml}$ RNaseA in PBS pH 7.4) for 15-20 min in dark at room temperature. Then, cells were examined in fluoroscope or used for flow cytometry analysis, with FACS calibur and analysis software CELLQuest (Becton Dickinson).

\section{Cell counting and MTT assay}

The effects of IL-16 to Jurkat cells were detected by cell counting and MTT assay. In cell counting experiment, $3 \mu \mathrm{l}$ of $1 \times 10^{6}$ Jurkat cells/ml were cultured in different concentrations of rIL-16-containing RPMI-1640 without serum for three days. Cell numbers were counted in a haemocytometer in the presence of $0.5 \%$ trypan blue. The experiment was repeated at least 6 times.

The specific inhibitors, $0.15 \mu M$ Bisindolylmaleimide (Bis) for PKC, $0.25 \mu M$ PD98059 (PD) for MEK, 8 mM SB203580 (SB) for p38, were added into medium $1.5 \mathrm{~h}$ before rIL-16 to examine the possible regulators and associated signal pathway responsible to the rIL-16 action in the cells. After $24 \mathrm{~h}$ treatment, cells were harvested for MTT assay. Briefly, MTT was dissolved at a concentration of $5 \mathrm{mg} / \mathrm{ml}$ in sterile PBS. Extraction buffer was composed of $20 \% \mathrm{~W} / \mathrm{V}$ of SDS (AMRESCO) in $50 \%$ of DMF (Fluka). pH was adjusted to 4.7 by adding $2.5 \%$ of $80 \%$ acetic acid and 2 . $5 \%$ of $1 \mathrm{~N} \mathrm{HCl}$. Each well was added $25 \mu \mathrm{l}$ MTT stock solution, incubated at $37^{\circ} \mathrm{C}$ for $4 \mathrm{~h}$, then added $100 \mu \mathrm{l}$ of the extraction buffer. After an overnight incubation at $37^{\circ} \mathrm{C}$, the optical densities at $570 \mathrm{nM}$ were measured using ELISA Microplate Reader (BIO-RAD Model 450). 


\section{RESULTS}

\section{rhIL-16}

The recombinant human IL-16 have been expressed and purified was a 130 a.a. fragment beginning from Met at site 502 and ended until 631 of pro-IL16, which has been shown to be sufficient for the biologic activity of IL-16[17],[18].

IL-16 expressing vector transformed BL21 (DE3) cells were cultured in Terric Broth medium. When the OD600 reached 0.6-0.7, $1 \mathrm{mM}$ IPTG was added to induce the expression of IL-16 for another $4 \mathrm{~h}$ before harvest. Coomassie blue staining of SDSPAGE of the harvested cell extract detected a protein with the proper $18 \mathrm{kD}$ molecular weight (Fig $1 \mathrm{~A})$. Western blot confirmed the $18 \mathrm{kD}$ protein specifically interact with anti-IL-16 monoclonal antibody (Fig 1B) indicating that the recombinant pro- tein showed the predicted molecular weight and immunological activities of human IL-16.

The recombinant IL-16 was further purified by affinity chromatography on $\mathrm{Ni}^{2+}$-NTA agarose (Qiagen), and was evaluated to be more than $95 \%$ purity by silver staining (data not shown). Fractions were tested for activation of PBMCs proliferation according to Parado's method[19], and the results confirmed that the recombinant IL-16 has the human IL-16 biologic activity (data not shown).

The effects of rhIL-16 on the growth of Jurkat T leukemia cells

To confirm the potential response activity of Jurkat cells to IL-16 treatment, the surface marker molecules of the cells was detected by flow cytometry with anti-CD4 and anti-CD8 monoclonal antibodies. As shown in Fig 2, the Jurkat cells used in the ex-

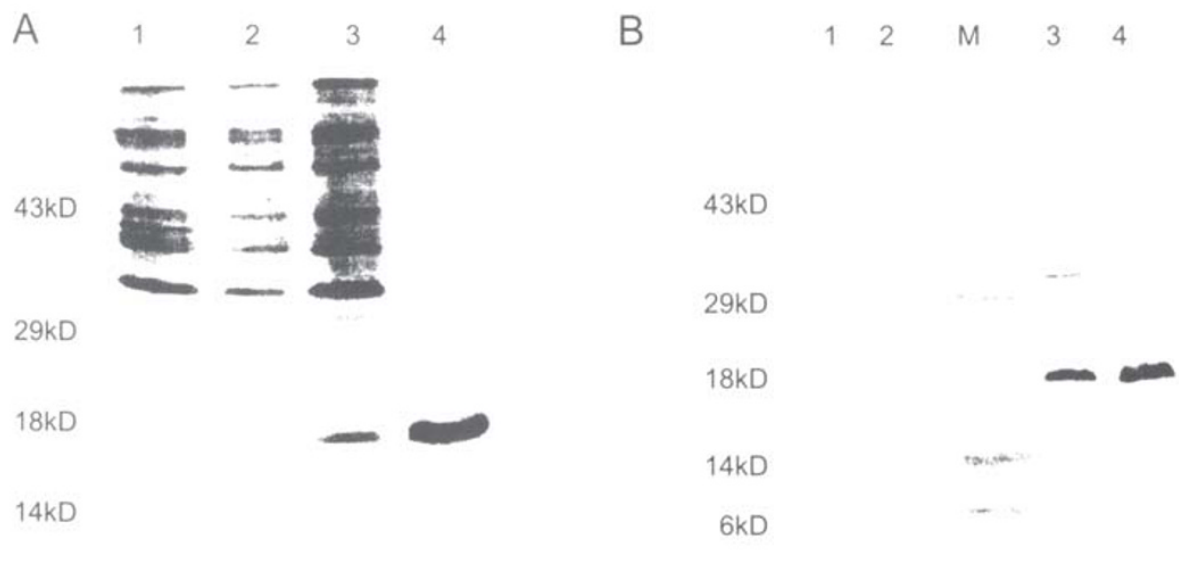

Fig 1. rIL-16 expression, purification and Western blot analysis

A. Coomassie blue-stained 12\% SDS-PAGE gel of E.coli BL-21 (DE3) cell lysate expressing recombinant human IL-16. Lane 1: untransformed BL-21 cell lysate; Lane 2: transformed by pT7-7His blank vector; Lane 3: total protein of pT7-7His-IL16 vector transformed BL-21 lysate. Cells were harvested after induction by $1 \mathrm{mM}$ IPTG for $4 \mathrm{~h}$; lane $4, \mathrm{Ni}^{+}$affinity chromatography purified rIL-16 protein from lysate of Lane 3. B. Western blot assay of rIL-16 expression. Lane 1, 2, 3, 4, same as Fig 1A. The IL-16 expression product is about $18 \mathrm{kD}$. Equal volumes of protein solutions were loaded in each lane.

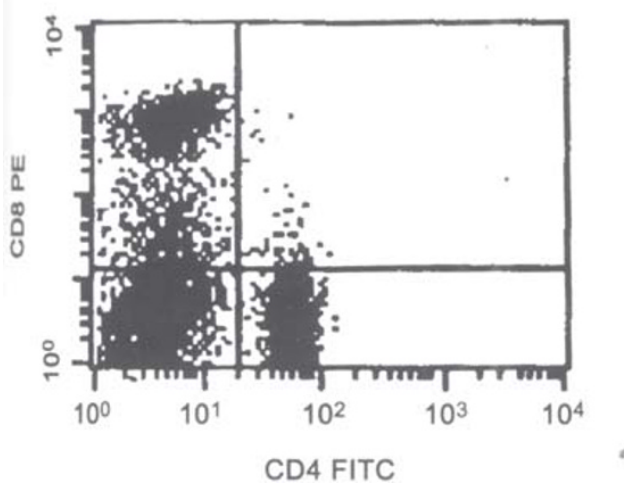

Fig 2. FACS analysis of surface markers of Jurkat cells FACS analysis was performed as described in Material and Method. Upleft (UL) represents $\mathrm{CD} 4 \mathrm{CD}^{+}$cells; $\mathrm{Up}$-right (UR) represents $\mathrm{CD} 4^{+} \mathrm{CD}^{+}$ cells;

Low-left (LL) represents CD4-CD8 cells; Low-right (LR) represents $\mathrm{CD} 4^{+} \mathrm{CD} 8$ - cells. 
periments were a population containing $41.56 \%$ of $\mathrm{CD} 4^{+}$cells, $27.02 \%$ of $\mathrm{CD}^{+}$cells and $1.54 \%$ of $\mathrm{CD} 4^{+}$ $\mathrm{CD}^{+}$cells. IL-16 is a native ligand to CD4; the rIL16 would be able to react with $\mathrm{CD} 4^{+}$Jurkat cells in the population.

The regulation effects of IL-16 on the growth of Jurkat cells were examined by cell counting and MTT assay. In the presence of $10^{-9} \mathrm{M}$ IL-16/L, the growth of Jurkat cells was estimated by cell counting at $24 \mathrm{~h}$ intervals for three days. To normalize the result, rectified average was calculated as following: Cell Number (with rIL-16 or not)/Cell number (without rIL-16). Control was defined as $100 \%$. As shown in Fig 3A, cells number increased gradually in the presence of $10^{-9} \mathrm{M}$ rIL-16 compared with control showing the stimulating activity of rIL-16 to
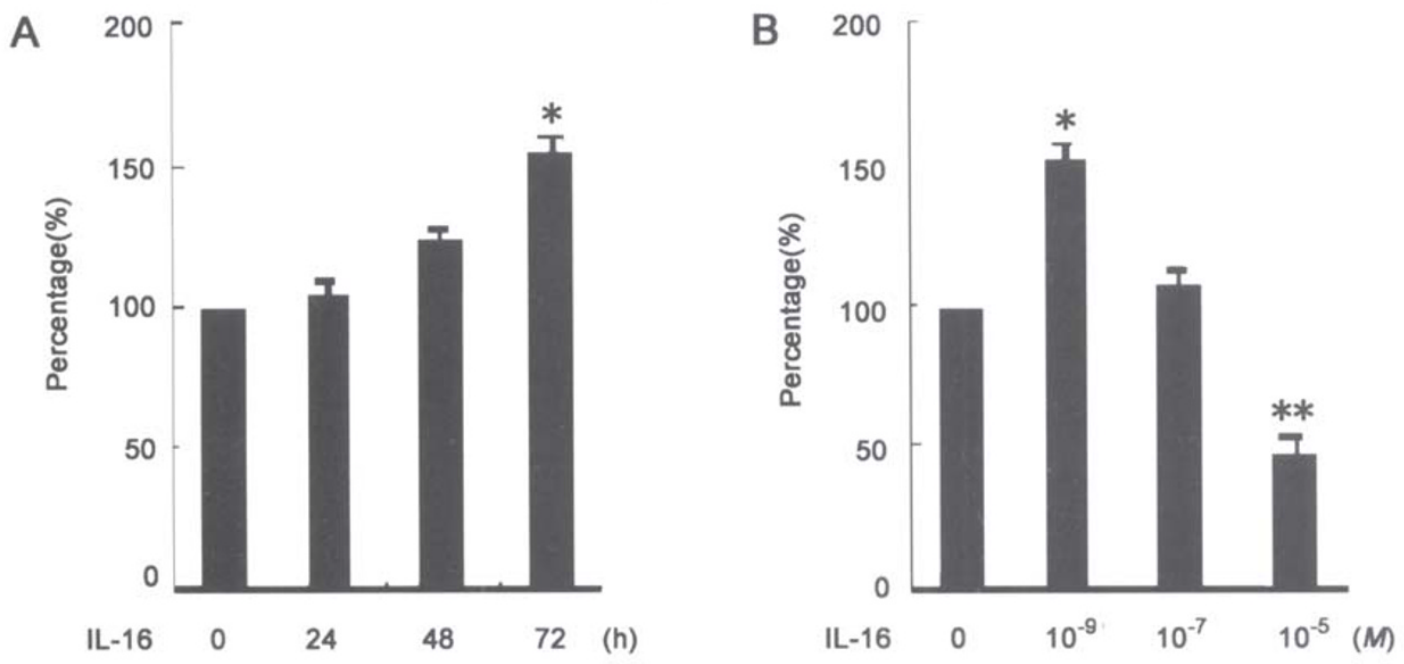

Fig 3. Effects of rIL-16 on Jurkat cell growth.

A.Cell number was detected by cell counting in the presence of $10^{-9} \mathrm{M}$ rIL-16 for 0, 24, 48, $72 \mathrm{~h}$. Rectified average of three experiments showed a significant increase of cell proliferation at $72 \mathrm{~h}$.

B.Cell number was detected by Cell counting with or without the presence of rIL-16 $\left(0,10^{-9} \mathrm{M}, 10^{-7} \mathrm{M}, 10^{-}\right.$ $\left.{ }^{5} M\right)$. Over three days, cell number was compared by rectified average with control. Rectified average showed a significant decrease in $10^{-5} \mathrm{M}$ rIL-16 treated cells. ${ }^{*} P<0.05,{ }^{*} * P<0.01$.

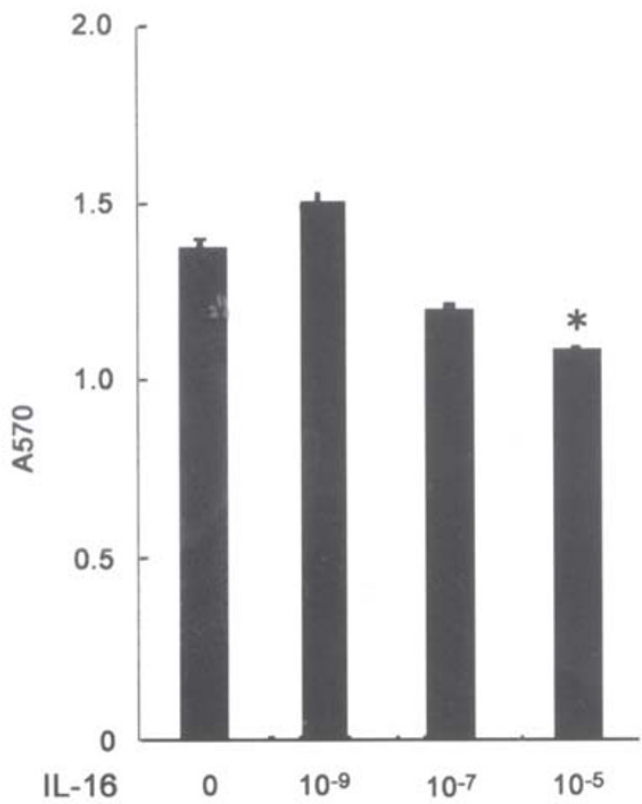

$(M)$
Fig 4. Effects of rIL-16 treatment for $24 \mathrm{~h}$ on Jurkat cell growth

Cell growth was detected by MTT assay in the presence or not of rIL-16 $\left(0,10^{-9} M, 10^{-7} M, 10^{-5} M\right)$. After 24 h treatment, cell viability was detected at OD570. Column chart showed an inhibition of cell viability in the highest rIL-16 $\left(10^{-5} \mathrm{M}\right)$ treatment. ${ }^{*} P<0.05$. 
A

\begin{tabular}{rr} 
Marker & $\%$ Gated \\
\hline All & 100.00 \\
apoptosis & 3.22
\end{tabular}

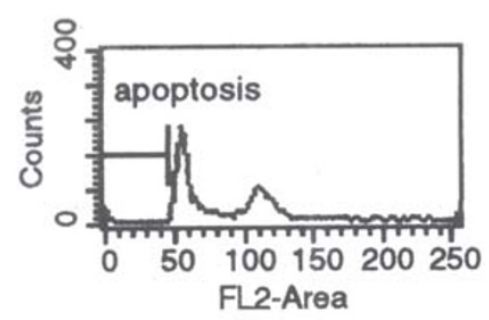

C

\begin{tabular}{rr} 
Marker & $\%$ Gated \\
\hline All & 100.00 \\
apoptosis & 4.34
\end{tabular}
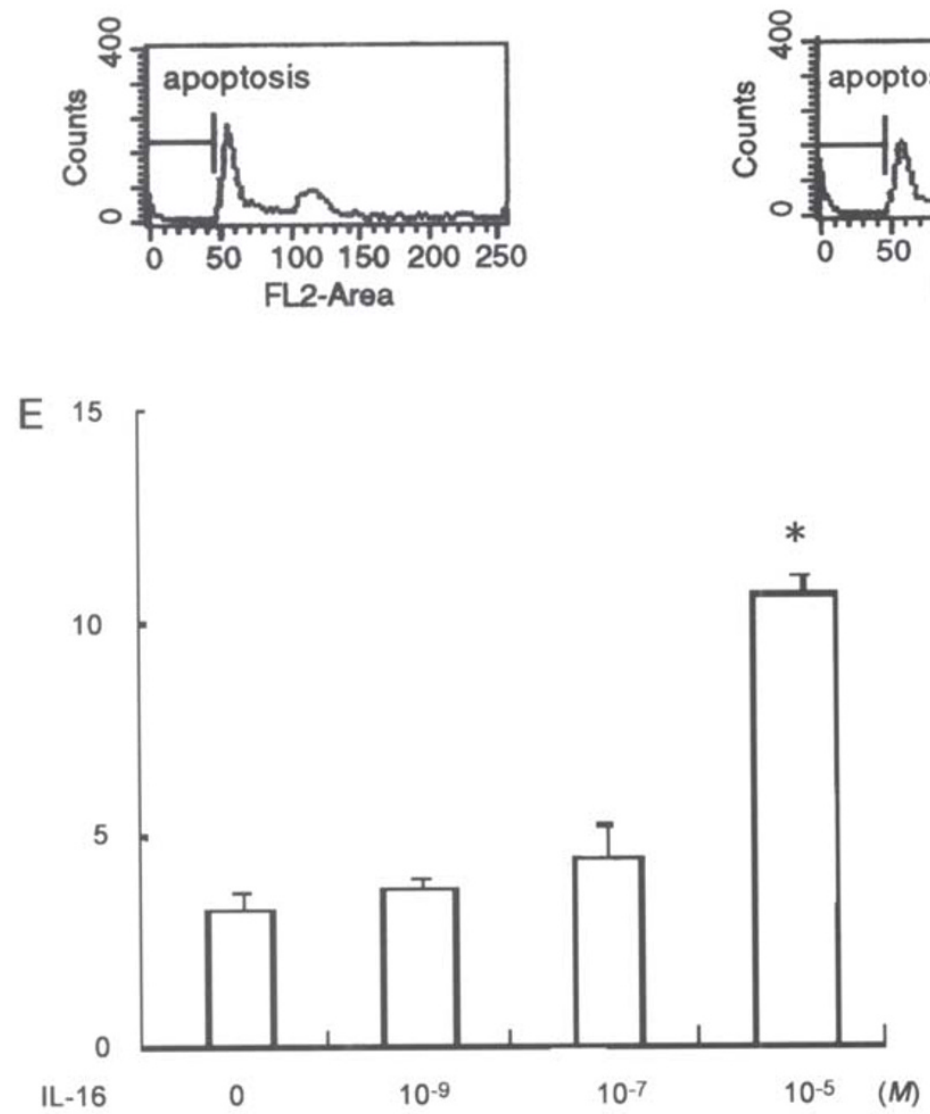

B

\begin{tabular}{rr} 
Marker & $\%$ Gated \\
\hline All & 100.00 \\
apoptosis & 4.80
\end{tabular}

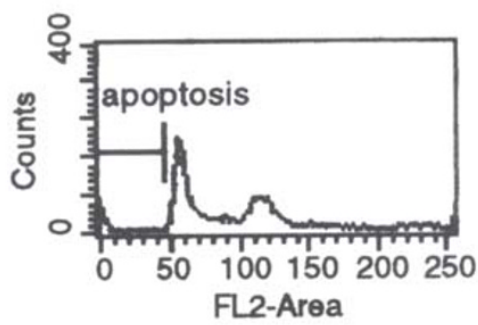

D \begin{tabular}{rr} 
Marker & $\%$ Gated \\
\cline { 2 - 2 } & All \\
apoptosis & 100.00
\end{tabular}

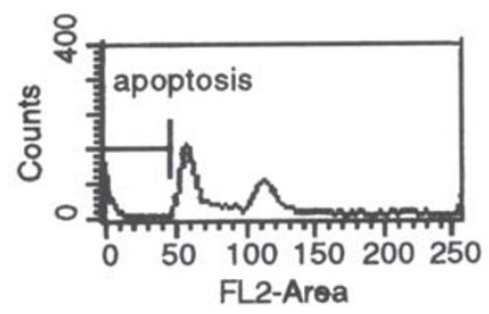

Fig 5. The apoptosis induced by rIL-16 in Jurkat cells A-D,? The representative data of FACS analysis. After treatment of 0 (A), $10^{-9}$ $M(\mathrm{~B}), 10^{-7} M(\mathrm{C}), 10^{-5} M$ (D) rIL-16 for 24 $\mathrm{h}$, the apoptosis of Jurkat cells was detected by PI staining and FACS analysis. E. The average of three experiments. ${ }^{*} P<0.01$.
Jurkat cells. Similar as cell counting, MTT assay also showed the time-dependent stimulating activity of $10^{-9} M$ rIL-16 on Jurkat cells (data notshown). However, increased amount of IL-16 (up to $10^{-5} \mathrm{M}$ / $\mathrm{L}$ ) in the medium indicated an inhibiting acion to
Jurkat cells as shown in Fig 3B. The results suggested that the rIL-16 affected the proliferation of Jurkat cells in a dose dependent manner. The cells number decreased $45 \%$ under the treatment of $10^{-}$ ${ }^{5} \mathrm{M} / \mathrm{L}$ of IL-12 for three days in contrast to control 
cells. Further evidence for the inhibiting effect of rIL-16 on Jurkat cell viability was also obtained by MTT assay. Under $24 \mathrm{~h}$ treatment of $10^{-5} \mathrm{M}$ rhIL16 , the growth of Jurkat cells was markedly inhibited. The result demonstrated that rIL-16 in higher dose $\left(10^{-5} M\right)$ had the inhibiting effect to the cells (Fig 4).

\section{Higher concentration rIL-16 treatment resulted in an enhanced apoptosis}

To Jurkat T leukemia cells, rIL-16 showed either growth-stimulating activity at low dose $\left(10^{-9} M\right)$ or growth-inhibiting activity at high dose $\left(10^{-5} M\right)$. The effects of $10^{-5} \mathrm{M}$ rIL-16 to Jurkat cells were further examined by DNA measurement of the cells. After treatment, the cells were stained with Propidium Iodide and run on FACS Calibur (Becton Dickinson, America) and analyzed by CELLQuest (Becton Dickson).

The FACS assay indicated a low ratio of spontaneous apoptosis of Jurkat cells in serum-free medium (Fig 5A). Low concentration $\left(10^{-9} M\right.$ and $\left.10^{-7} M\right)$ of rIL-16 treatment showed no significant change of cell apoptosis in $24 \mathrm{~h}$ (Fig 5B, C). But, under $10^{-}$ ${ }^{5} \mathrm{M}$ rIL-16 treatment for $24 \mathrm{~h}$, apoptotic cells ratio was increased to $10.08 \%$ (Fig 5D). Fig $5 \mathrm{E}$ shows the average result of three experiments. It has been reported recently that the activation of $\mathrm{CD}^{+} \mathrm{T}$ cells induced the expression of CD4[20]. We have not
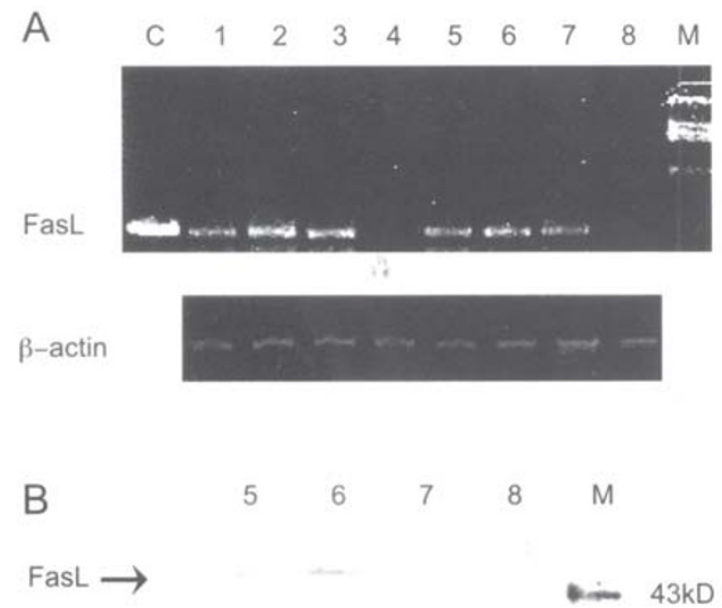

examined the induction of CD4 molecule on $\mathrm{CD}^{+}$ cells in Jurkat cells in the presence of rIL-16. In rIL-16 treated Jurkat cell population, the real apoptotic cells of total $\mathrm{CD} 4^{+}$target cells might be more than $10.08 \%$.

Apoptosis induced by rIL-16 may be Fas/FasL pathway independent, but Bid and c-Myc associated in Jurkat cells

To identify the death signal molecules activated in apoptosis caused by rIL-16, we first analyzed the possible role of Fas/FasL pathway. Because Fas was constitutively expressed on the lymphocyte cell surface[21], we measured the FasL expression level in the Jurkat cells under the treatment of IL-16 by RTPCR. As shown in Fig 6A, the Jurkat cells endogenously expressed FasL, and maintained the expression level in low dose rIL-16-containing medium. However, incubation with $10^{-5} M$ rIL-16 for $24 \mathrm{~h}$ demonstrated a markedly inhibition of FasL mRNA expression in the cells.

Western blot showed a similar results (Fig 6B) indicating the FasL protein could only be detected in control cells and the $10^{-9} \mathrm{M}$ rIL-16 treated cells, but not in the $10^{-7} \mathrm{M}$ and $10^{-5} \mathrm{M}$ rIL-16 treated cells. Our results suggested that Fas/FasL death receptor mechanism seems not to be responsible for the apoptosis induced by rIL-16 in Jurkat cells.
Fig 6. Effects of rIL-16 on FasL expression in Jurkat T cells

Jurkat cells were incubated with rIL-16 for 15 and 24h. The Fasl expressionwas detected by RT-PCR(A) and Western Blot assay (B).

A. Upper panel showed FasL expression. Lane C, positive control; Lanes 1, 2, 3, 4 represent 0 , $10^{-9}, 10^{-7}, 10^{-5} \mathrm{M}$ rIL-16 treatment for $15 \mathrm{~h}$; Lanes $5,6,7,8$, represent $0,10^{-9}, 10^{-7}, 10^{-5} M$ rIL-16 treatment for $24 \mathrm{~h}$. M was Markers. The lower panel was the PCR result by $\beta$-actin primer as loading control.

B. FasL protein expression. Jurkat T cells were treated with rIL-16 at various doses. Lanes 5, $6,7,8$, represent $0,10^{-9}, 10^{-7}, 10^{-5} \mathrm{M}$ rIL-16 treatment for $24 \mathrm{~h}$. Equal amount of protein was loaded on a $12 \%$ SDS-PAGE. The expression level was analyzed by anti-FasL antibody. M was $43 \mathrm{Kd}$ protein marker. 
Bcl-2 family members bearing only the $\mathrm{BH} 3$ domain are essential inducers of apoptosis. The BH3-only protein Bid is one of the most important molecules in programmed cell death. We analyzed the expression of Bid in rIL-16 treated Jurkat cells. RT-PCR results definitely revealed the stimulation of higher expression of Bid in Jurkat cells after $10^{-5} \mathrm{M}$ rIL-16 treatments for $24 \mathrm{~h}$ (Fig 7) as compared with un-detectable signal in control cells and low dose $\left(10^{-9} M\right)$ rIL-16 treated cells.

As a transcript factor, c-Myc is a critical molecule in transmitting up-stream signals into proliferation or apoptosis effects by a series of regulating genes. The c-Myc expression in rIL-16 driven Jurkat cells was also examined by RT-PCR. As shown in Fig 7, c-myc transcripts were undetectable in the control cells and $10^{-9} \mathrm{M}$ or $10^{-7} \mathrm{M}$ of rIL-16 treated cells, but up-regulated expression of c-myc occurred in $10^{-5} \mathrm{M}$ rIL-16 induced Jurkat cells. We, therefore, postulated that c-Myc over-expression in rIL-16 treated Jurkat cells might be also responsible to the apoptosis of the cells.

Signal transduction pathway involved in rIL-16 action on Jurkat cells

To understand the signal pathways involved in the growth-stimulating or growth-inhibiting activities of rIL-16 on Jurkat cells, the possible role of PKC and ERK were investigated.

Bid

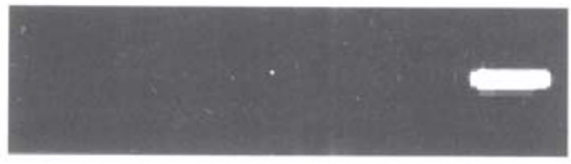

C.Myc

$\beta$-actin
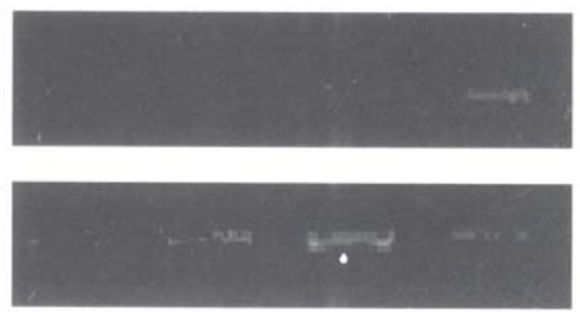

Fig 7. rIL-16 induced expression of Bid and c-Myc detected by RT-PCR

Jurkat cells were cultured for $24 \mathrm{~h}$ in the presence or not of rIL-16. Lanes 1, 2, 3, 4 represent $0,10^{-9}, 10^{-7}, 10^{-5} \mathrm{M}$ rIL-16 treatment for $24 \mathrm{~h}$, respectively. Expression level of Bid and c-myc were quantified by RT-PCR using specific primers. $\beta$ actin levels were used to monitor the equal amount template being used.
PKC is a $\mathrm{Ca}^{2+}$ dependent Ser/Thr kinase. It is activated in cell proliferation, differentiation, and migration[10]. We used the PKC specific inhibitor Bisindolylmaleimide (Bis) to analyze its action in rIL16 treated Jurkat cells. In the presence of $0.15 \mu M$ Bis, cells viability under the treatment of different concentration of rIL-16 was measured by MTT assay. The data showed in Fig 8 indicated that the proliferation of cells dropped rapidly in the presence of Bis in all of the rIL-16 treated cells, but little change was found in rIL-16 not treated cells. This result suggested that the growth regulation activity of rIL16 on Jurkat cells might be associated with the activation of $\mathrm{PKC}$ in the cells. The blocking of $\mathrm{PKC}$ activity by Bis inhibited partially the proliferation of rIL-16 treated Jurkat cells, in comparison, no effect was found in control cells without rIL-16 treatment. The results reflected the dominant inhibitory effect of Bis on cell proliferation in this situation indicating PKC must take a role in triggering proliferation in the Jurkat cells induced by rIL-16.

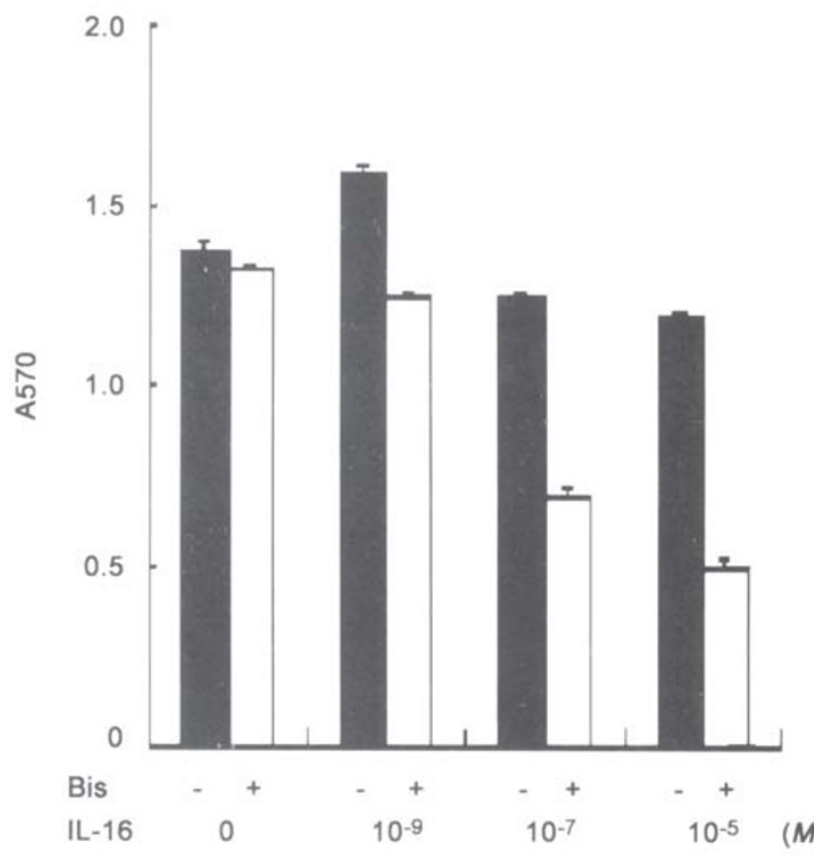

Fig 8. Block of rIL-16 treated Jurkat cell proliferation by Bisindolymaleimide (Bis)

PKC inhibitor Bis was added $1.5 \mathrm{~h}$ before rIL-16 induction to block the action of PKC in the regulation of Jurkat cell growth. MTT assay measured the decrease of cell growth in rIL-16 treated Jurkat cells. 
Mitogen-activated protein kinase (MAPK) cascades have been shown to play a key role in transduction of extracellular signals to cellular responses. At least three MAPK families have been found and characterized: extra-cellular signal-regulated kinase (ERK), Jun kinase (JNK/SAPK) and p38 MAPK. We used the MEK1-specific inhibitor, PD 98059, and the p38 specific inhibitor, SB 203580, to analyze the mechanism of IL-16 induced apoptosis in Jurkat cells. Jurkat cells were incubated with $50 \mathrm{mM}$ PD98059 or $8 \mu M$ SB203580 before IL-16 treatment, the cell growth was determined by MTT assay. Fig 9 showed that the addition of PD98059 dominantly prevented the cells from apoptosis induced by IL-16. No effect was detectable in the SB203580 treated cells (data not shown). The result implied that the MEK1 might be involved in apoptosis signal delivery in Jurkat cells.

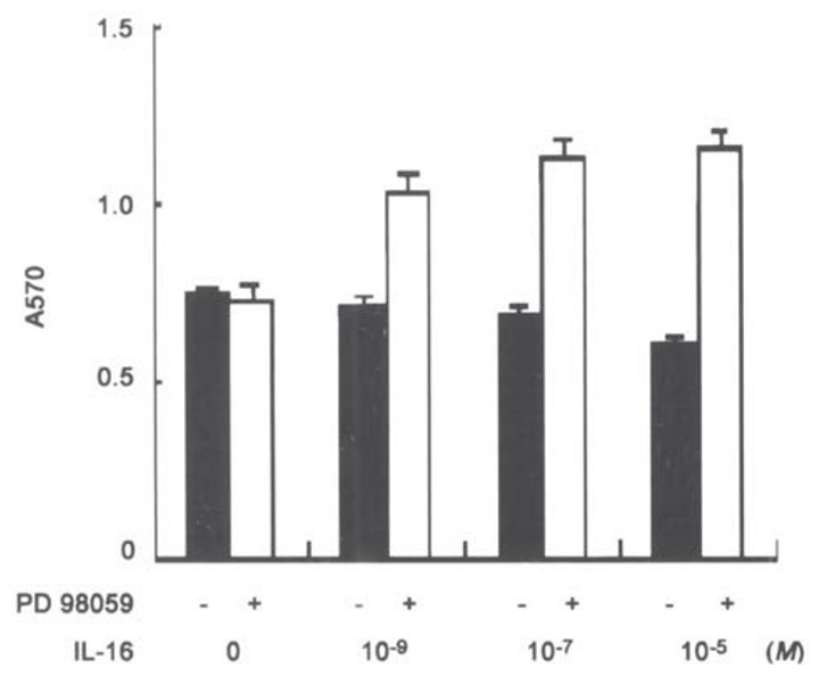

Fig 9. Block of rIL-16 induced growth-suppressing effect by PD 98059 in Jurkat cells

The MEK1 inhibitor PD98059 was added $1.5 \mathrm{~h}$ before rIL16 treatment. MTT assay was used to measure the growth of the cells.

\section{DISCUSSION}

Human IL-16 functions as a pleiotropic regulator stimulating the proliferation, activation, chemotaxis and programmed cell death on $\mathrm{T}$ lymphocytes. The signals to $\mathrm{T}$ cell are all mediated by its natural receptor CD4. The role of CD4 in the regulation of cell activation and death is pretty complex.

We report here the recombinant IL-16 may stimu- late the proliferation of Jurkat T leukemia cells at $10^{-9} \mathrm{M}$ and potentially inhibit the cell growth accompanied by an increased apoptosis under $10^{-5} \mathrm{M}$ of IL-16 induction. The inhibiting effects of IL-16 on CD3dependent lymphocyte activation and proliferation were previously reported[8],[22]. Cross-linking of the CD4 molecule by anti-CD4 mAb or by HIV envelope protein gp120 has been shown to prime resting CD4 ${ }^{+} \mathrm{T}$ lymphocytes for apoptosis[24],[25]. While the opposite effects on activated $\mathrm{T}$ cell was also observed, ligation of CD4 by anti-CD4 mAb or HIV1 gp120 drastically inhibited subsequent AICD (Activation Induced Cell Death) of human T cell clones triggered through CD3/TCR, due to the prevention of up regulation of FasL[25],[26]. Similarly, CD3/CD4 co-ligation was shown to inhibit T-cell activation in the absence of a costimulus in mouse lymphocytes[27]. In a word, the presence of costimulus and the subsequent events of stimulus may direct the cell to activation or death. Based on these former results, it could be postulated that IL-16 may also function as a stimulus for apoptosis besides its activation effect on $\mathrm{CD} 4^{+} \mathrm{T}$ cells.

Various members of the interleukin family, like IL-2, have been shown to possess both anti-apoptotic and pro-apoptotic stimulation activity[16]. IL-2 can induce proliferation in most circumstances, but it has also been reported that IL-2 can down-regulate the caspase-8 inhibitor c-FLIP[23], and up-regulate FasL[16], both molecules can prime cells for death.

Several studies have shown the expression and interaction of Fas and FasL can result in the autocrine stimulation of Fas/FasL death pathway in AICD in T hybridoma cells and activated T cells. Because Jurkat cells constitutively express Fas at their surface and are sensitive to Fas-induced apoptosis[21], our research focuses on FasL expression. Surprisingly, rIL-16 doesn' t up-regulate FasL, which correlate with AICD in Jurkat cells caused by most stimulators[21], [29-32], but does down regulate its expression on both RNA and protein level. Although several studies have shown that the expression and interaction of Fas and FasL is required for AICD of activated T cells. But, Fas/FasL pathway is not an absolute requirement for death control[33]. These results also hint that there may be another apoptosis pathway functioning in the IL16 mediated effects.

We found that c-myc and Bid expression level were 
up regulated by IL-16. This result suggested that cMyc might be involved in the process to activate certain cell death associated genes, but not FasL in this case. The Bcl-2 family proteins consist of both antagonists and agonists that regulate the apoptosis by competing through dimerization. Over-expression of Bcl-2 suppresses Fas-mediated apoptosis in human hepatocellular carcinoma BEL-7404 cells and Trailinduced apoptosis in Jurkat cells[34],[35]. Bid, one of the $\mathrm{BH} 3$ domain-containing molecules, promotes cell death after binding with Bcl-2[34],[36]. The upregulation of Bid in IL-16 treated Jurkat cells implied the involvement of Bid molecule in the cell death through other death receptors, tumor necrosis factor or Trail etc.

To figure out the special pathways associated with the regulation activity of IL-16 in Jurkat cells, we found that PKC was activated after IL-16 treatment, and ERK pathway is also required for control of rIL16 induced Jurkat cell death. It has been reported that the ERK pathway is activated during AICD upon stimulation of the T cell receptor-CD3 complex [37]. However, the IL-16 activates the stress activated protein kinase (SAPK) pathway and p38 MAPK, but, not ERK, in $\mathrm{CD}^{+}{ }^{+}$macrophages. The IL-16 mediated activation of SAPKs and p38 in macrophages alone does not induce a detectable apoptotic cell death [38]. Our results suggest that, in Jurkat T leukemia cells, the ERK pathway is responsible for the rIL16-induced cell death. PKC pathway and ERK pathway have a common regulated molecule, nur77[37], [39], which is an orphan nuclear steroid receptor [40]. It transmitted the signal to apoptosis related gene through protein-protein interaction [41]. We have not elucidated every molecule in these signal pathways, but the signal is probably transducted by both PKC and ERK pathway and regulated the effect to proliferation or apoptosis. From our result, the high concentration of IL-16 $\left(10^{-5} M\right)$ can induce $\mathrm{CD}^{+} \mathrm{T}$ cell apoptosis without any other prestimulation, although no significant difference was observed in the lower concentration IL-16 (10-9 M) treatment. So a dual role happened to IL-16 in Jurkat cells. The cytokine can stimulate cells proliferation and activation, but also induce apoptosis under certain conditions. It might be a kind of dose effect, but the signal pathway participation makes it looks like a special biological activity. So the function of
IL-16 in CD4 ${ }^{+} \mathrm{T}$ cells needs to be further elucidated.

\section{ACKNOWLEDGMENTS}

We thank Mrs. Wan Li JIANG for her assistance for Cell culture techniques. This work was supported by Major State Basic Research (973) Program of China (G1999053905).

\section{REFERENCES}

[1] Zhang Y, Center DM, Wu DM, Cruikshank WW, Yuan J, Andrews DW, Kornfeld H. Processing and activation of pro-interleukin-16 by caspase-3. J Biol Chem 1998; 273: 1144-9.

[2] Baier M, Bannert N, Werner A, Lang K, Kurth R. Molecular cloning, sequence, expression, and processing of the interleukin 16 precursor. Proc Natl Acad Sci USA 1997; 94:5273-7.

[3] Zhang Y, Kornfeld H, Cruikshank WW, Kim S, Reardon CC, Center DM. Nuclear translocation of the N-terminal prodomain of interleukin-16. J Biol Chem 2001; 276: 1299-303.

[4] Cruikshank WW, Center DM, Nisar N, Wu M, Natke B, Theodore AC, Kornfeld H. Molecular and functional analysis of a lymphocyte chemoattractant factor: association of biologic function with CD4 expression. Proc Natl Acad Sci USA 1994; 91:5109-13.

[5] Nicoll J, Cruikshank WW, Brazer W, Liu Y, Center DM, Kornfeld H. Identification of domains in IL-16 critical for biological activity. J Immunol 1999; 163:1827-32.

[6] Center DM, Kornfeld H and Cruikshank WW, Interleukin 16 and its function as a CD4 ligand. Immunol Today1996; 17:476

[7] Bellini A, Yoshimura H, Vittori E, Marini M, Mattoli S. Bronchial epithelial cells of patients with asthma release chemoattractant factors for T lymphocytes. J Allergy Clin Immunol 1993; 92:412-24.

[8] Theodore AC, Center DM, Nicoll J, Fine G, Kornfeld H, Cruikshank WW. CD4 ligand IL-16 inhibits the mixed lymphocyte reaction. J Immunol 1996; 157:1958-64.

[9] Ryan TC, Cruikshank WW, Kornfeld H, Collins TL, Center DM. The CD4-associated tyrosine kinase p56lck is required for lymphocyte chemoattractant factor-induced T lymphocyte migration. J Biol Chem 1995; 270:17081-6.

[10] Cruikshank WW, Greenstein JL, Theodore AC, Center DM. Lymphocyte chemoattractant factor induces CD4dependent intracytoplasmic signaling in lymphocytes. J Immunol 1991; 146:2928-34.

[11] Tuosto L, Piazza C, Moretti S, Modesti A, Greenlaw R, Lechler R, Lombardi G, Piccolella E. Ligation of either CD2 or CD28 rescues CD4 ${ }^{+} \mathrm{T}$ cells from HIV-gp120induced apoptosis. Eur J Immunol 1995; 25:2917-22.

[12] Tuosto L, Montani MS, Lorenzetti S, Cundari E, Moretti S, Lombardi G, Piccolella E. Differential susceptibility to monomeric HIV gp120-mediated apoptosis in antigen-activated $\mathrm{CD} 4^{+} \mathrm{T}$ cell populations. Eur J Immunol 1995; 25:2907-16.

[13] Westendorp MO, Frank R, Ochsenbauer C, Stricker K, 
Dhein J, Walczak H, Debatin KM, Krammer PH. Sensitization of T cells to CD95-mediated apoptosis by HIV-1 Tat and gp120. Nature 1995; 375:497-500.

[14] Corbeil J, Richman DD. Productive infection and subsequent interaction of CD4-gp120 at the cellular membrane is required for HIV-induced apoptosis of CD4+ T cells. J Gen Virol 1995; 76 ( Pt 3):681-90.

[15] Radrizzani M, Accornero P, Amidei A, Aiello A, Delia D, Kurrle R, Colombo MP. IL-12 inhibits apoptosis induced in a human Th1 clone by gp120/CD4 cross-linking and CD3/TCR activation or by IL-2 deprivation. Cell Immunol 1995; 161:14-21.

[16] Refaeli Y, Van Parijs L, London CA, Tschopp J, Abbas AK. Biochemical mechanisms of IL-2-regulated Fas-mediated T cell apoptosis. Immunity. 1998; 8:615-23.

[17] Baier M, Werner A, Bannert N, Metzner K, Kurth R. HIV suppression by interleukin-16. Nature 1995; 378:563.

[18] Zhou P, Goldstein S, Devadas K, Tewari D, Notkins AL. Human $\mathrm{CD}^{+}$cells transfected with IL-16 cDNA are resistant to HIV-1 infection: inhibition of mRNA expression. Nat Med 1997; 3:659-64.

[19] Parada NA, Center DM, Kornfeld H, Synergistic activation of CD4 ${ }^{+}$T cells by IL-16 and IL-2, J. Immunol 1998; 160:2115-20

[20] Kitchen SG, LaForge S, Patel VP, Kitchen CM, Miceli MC, Zack JA. Activation of CD8 T cells induces expression of CD4, which functions as a chemotactic receptor. Blood 2002; 99:207-12.

[21] Dhein J, Walczak H, Baumler C, Debatin KM, Krammer PH. Autocrine T-cell suicide mediated by APO-1/(Fas/ CD95). Nature 1995; 373:438-41.

[22] Cruikshank WW, Lim K, Theodore AC, Cook J, Fine G, Weller PF, Center DM. IL-16 inhibition of CD3-dependent lymphocyte activation and proliferation. J Immunol 1996; 157:5240-8.

[23] Irmler M, Thome M, Hahne M, Schneider P, Hofmann K, Steiner V, Bodmer JL, Schroter M, Burns K, Mattmann C, Rimoldi D, French LE, Tschopp J. Inhibition of death receptor signals by cellular FLIP. Nature 1997; 388: 190-5.

[24] Newell MK, Haughn LJ, Maroun CR, Julius MH. Death of mature T cells by separate ligation of CD4 and the Tcell receptor for antigen. Nature 1990; 347:286-9.

[25] Banda NK, Bernier J, Kurahara DK, Kurrle R, Haigwood N, Sekaly RP, Finkel TH. Cross-linking CD4 by human immunodeficiency virus gp120 primes T cells for activation-induced apoptosis. J Exp Med 1992; 176:1099-106.

[26] Oberg HH, Sanzenbacher R, Lengl-Janssen B, Dobmeyer T, Flindt S, Janssen O, Kabelitz D. Ligation of cell surface CD4 inhibits activation-induced death of human T lymphocytes at the level of Fas ligand expression. J Immunol 1997; 159:5742-9.

[27] Sanzenbacher R, Kabelitz D, Janssen O. SLP-76 binding to p56lck: a role for SLP-76 in CD4-induced desensitiza- tion of the TCR/CD3 signaling complex. J Immunol 1999; 63:3143-52.

[28] Portoles P, de Ojeda G, Criado G, Fernandez-Centeno E, Rojo JM. Antibody-induced CD3-CD4 coligation inhibits TCR/CD3 activation in the absence of costimulatory signals in normal mouse CD4(+) T lymphocytes. Cell Immunol 1999; 195:96-109.

[29] Friesen C, Herr I, Krammer PH, Debatin KM. Involvement of the CD95 (APO-1/FAS) receptor/ligand system in drug-induced apoptosis in leukemia cells. Nat Med 1996; 2:574-7. [30] Russell JH, Rush B, Weaver C, Wang R. Mature T cells of autoimmune lpr/lpr mice have a defect in antigen-stimulated suicide. Proc Natl Acad Sci USA 1993; 90:4409-13.

[31] Brunner T, Mogil RJ, LaFace D, Yoo NJ, Mahboubi A, Echeverri F, Martin SJ, Force WR, Lynch DH, Ware CF. Cell-autonomous Fas (CD95)/Fas-ligand interaction mediates activation-induced apoptosis in T-cell hybridomas. Nature 1995; 373:441-4.

[32] Ju ST, Panka DJ, Cui H, Ettinger R, el-Khatib M, Sherr DH, Stanger BZ, Marshak-Rothstein A. Fas(CD95)/FasL interactions required for programmed cell death after T-cell activation. Nature 1995; 373:444-8.

[33] Idziorek T, Khalife J, Billaut-Mulot O, Hermann E, Aumercier M, Mouton Y, Capron A, Bahr GM. Recombinant human IL-16 inhibits HIV-1 replication and protects against activation-induced cell death (AICD). Clin Exp Immunol 1998; 112:84-91.

[34] Chang YC, Xu YH. Expression of Bcl-2 inhibited Fasmediated apoptosis in human hepatocellular carcinoma BEL-7404 cells. Cell Research 2000; 10:233-42.

[35] Guo BC, Xu YH. Bcl-2 over-expression and activation of protein kinase $\mathrm{C}$ suppress the Trail-induced apoptosis in Jurkat cells. Cell Research 2001; 11:101-6.

[36] Yin XM. Signal transduction mediated by Bid, a prodeath Bcl-2 family proteins, connects the death receptor and mitochondria apoptosis pathways. Cell Research 2000; 10:161-7.

[37] van den Brink MR, Kapeller R, Pratt JC, Chang JH, Burakoff SJ. The extracellular signal-regulated kinase pathway is required for activation-induced cell death of T cells. J Biol Chem 1999; 274:11178-85.

[38] Krautwald S. IL-16 activates the SAPK signaling pathway in $\mathrm{CD}^{+}$macrophages. J Immunol 1998; 160:5874-9.

[39] Woronicz JD, Lina A, Calnan BJ, Szychowski S, Cheng L, Winoto A. Regulation of the Nur77 orphan steroid receptor in activation-induced apoptosis. Mol Cell Biol 1995; 15:6364-76.

[40] Winoto A. Genes involved in T-cell receptor-mediated apoptosis of thymocytes and T-cell hybridomas. Semin Immunol 1997; 9:51-8.

[41] Winoto A. Molecular characterization of the Nur77 orphan steroid receptor in apoptosis. Int Arch Allergy Immunol 1994; 105:344-6. 